\title{
Biological evaluation of hydroxynaphthoquinones as anti-malarials
}

\author{
Desiree C Schuck ${ }^{1}$, Sabrina B Ferreira ${ }^{2,3}$, Laura N Cruz ${ }^{1}$, David R da Rocha ${ }^{2}$, Miriam S Moraes ${ }^{1}$, Myna Nakabashi ${ }^{1}$, \\ Philip J Rosenthal ${ }^{4}$, Vitor F Ferreira ${ }^{2}$ and Celia RS Garcia ${ }^{1,5^{*}}$
}

\begin{abstract}
Background: The hydroxynaphthoquinones have been extensively investigated over the past 50 years for their anti-malarial activity. One member of this class, atovaquone, is combined with proguanil in Malarone ${ }^{\varpi}$, an important drug for the treatment and prevention of malaria.

Methods: Anti-malarial activity was assessed in vitro for a series of 3-alkyl-2-hydroxy-1,4-naphthoquinones (N1-N5) evaluating the parasitaemia after 48 hours of incubation. Potential cytotoxicity in HEK293T cells was assessed using the MTT assay. Changes in mitochondrial membrane potential of Plasmodium were measured using the fluorescent dye Mitrotracker Red CMXROS.
\end{abstract}

Results: Four compounds demonstrated $\mathrm{IC}_{50}$ in the mid-micromolar range, and the most active compound, N3, had an IC 50 of $443 \mathrm{nM}$. N3 disrupted mitochondrial membrane potential, and after 1 hour presented an IC $\mathrm{C}_{50 \Delta \psi_{\text {mit }}}$ of $16 \mu \mathrm{M}$. In an in vitro cytotoxicity assay using HEK 293T cells N3 demonstrated no cytotoxicity at concentrations up to $16 \mu \mathrm{M}$.

Conclusions: N3 was a potent inhibitor of mitochondrial electron transport, had nanomolar activity against cultured Plasmodium falciparum and showed minimal cytotoxicity. N3 may serve as a starting point for the design of new hydroxynaphthoquinone anti-malarials.

Keywords: Plasmodium falciparum, Hydroxynaphthoquinone, 2-hydroxy-1,4-naphthoquinone, Mitochondria, Malaria, Plasmodium berghei

\section{Background}

Despite the worldwide effort to understand molecular and cellular features of Plasmodium falciparum, the main aetiological agent of human malaria, the disease is still devastating. Parasite resistance to older anti-malarials raises the need for the development of new drugs [1,2]. The anti-malarials currently used stem from six drug classes: aminoquinolines, arylaminoalcohols, artemisinins, antifolates, antibiotics and inhibitors of the respiratory chain $[3,4]$. The last class is the subject of this report.

The hydroxynaphthoquinones have been extensively investigated over the past 50 years for their anti-malarial activity [5]. Hydrolapachol was the first hydroxynaphthoquinone

\footnotetext{
*Correspondence: cgarcia@usp.br

'Departamento de Fisiologia, Universidade de São Paulo, São Paulo 05508-900, Brazil

${ }^{5}$ Universidade de São Paulo, Instituto de Biociências, Rua do Matão, travessa 14, n.321 Cidade Universitária, CEP 05508-900 São Paulo, SP, Brazil Full list of author information is available at the end of the article
}

discovered that possessed anti-malarial activity [6]. This discovery, which emerged at a time of great interest in the study of hydroxynaphthoquinone derivatives as potential new anti-malarials, resulted in the synthesis of a large family of different hydrolapachol analogs [7]. Work on the antimalarial properties of hydroxynaphthoquinones was revived when chloroquine resistance emerged, and it was discovered that atovaquone effectively inhibits plasmodial electron transport at the ubiquinone (coenzyme Q, 2) site [8].

Atovaquone is a hydroxynaphthoquinone that is used in combination with proguanil (Malarone ${ }^{\circ}$ ) for prophylaxis and therapy of uncomplicated malaria [9]. Atovaquone has excellent anti-malarial activity but exhibits poor pharmaceutical properties, such as low bioavailability and high plasma protein binding [10]. To improve drug bioavailability, several atovaquone analogs were prepared and changes were made to the naphthoquinone moiety, especially the alkyl side chain, because it is known that modifying this

\section{Biomed Central}

(c) 2013 Schuck et al.; licensee BioMed Central Ltd. This is an Open Access article distributed under the terms of the Creative Commons Attribution License (http://creativecommons.org/licenses/by/2.0), which permits unrestricted use, distribution, and reproduction in any medium, provided the original work is properly cited. 
chain can alter drug activity [7] and counteract drug resistance [11-13]. Recently, it was demonstrated that 2methyl-heptyl or 2-methyl-heptyl-trifluoromethyl 2-hydroxy1,4-naphthoquinones were highly effective against atovaquone-resistant $P$. falciparum [14].

The aim of this work was to test the activity of a new series of hydroxynaphthoquinones [15] against $P$. falciparum. One of these compounds, $\mathrm{N} 3$, had an $\mathrm{IC}_{50}$ against cultured $P$. falciparum in the $\mathrm{nM}$ range, disrupted mitochondrial membrane potential, and had low toxicity against human cells suggesting potential as a lead compound for the development of new anti-malarial agents.

\section{Methods}

Chemistry

The hydroxynaphthoquinones N1-5 were recently synthesized using a new methodology [15].

\section{In vitro culture of $P$. falciparum}

3D7 strain parasites were cultured and synchronized as described previously [16,17]. Briefly, parasites were routinely maintained in $\mathrm{A}^{+}$human erythrocytes (1-3\% parasitaemia and $2 \%$ haematocrit) in RPMI-1640 media supplemented with $0.2 \%$ sodium bicarbonate, $50 \mathrm{mg} / \mathrm{L}$ hypoxanthine and $10 \%$ type $\mathrm{A}+$ human serum in $92 \% \mathrm{~N}_{2}, 5 \% \mathrm{CO}_{2}$ and $3 \% \mathrm{O}_{2}$.

\section{Cell culture of HEK293T}

HEK293T (human embryonic kidney) cells were cultured in $75 \mathrm{~cm}^{2}$ vented tissue culture flasks at $37^{\circ} \mathrm{C}$ in a humidified atmosphere containing $5 \% \mathrm{CO}_{2}$ in Dulbecco's modified essential medium (Gibco BRL) supplemented with $10 \%(\mathrm{v} / \mathrm{v})$ foetal bovine serum, $100 \mathrm{U} / \mathrm{ml}$ penicillin/ and $100 \mu \mathrm{g} / \mathrm{ml}$ streptomycin.

\section{Flow cytometry analysis}

Infected erythrocytes at the ring stage were incubated with different concentrations of the test compounds (N1-N5 $0.005,0.015,0.045,0.137,0.411,1.23,3.70,11.11,33.33$ and $100 \mu \mathrm{M}$ and atovaquone $0.005,0.015,0.045,0.137$, $0.411,1.23,3.70,11.11,33.33$ and $100 \mathrm{nM}$ ) for 48 hours; fixed in $2 \%$ paraformaldehyde in phosphate-buffered saline (PBS) for 24 hours; permeabilized with $0.1 \%$ Triton $\mathrm{X}-100$ and $20 \mu \mathrm{g} / \mathrm{ml}$ RNase; incubated for 30 minutes at $37^{\circ} \mathrm{C}$; and stained with $1 \mathrm{nM}$ Yoyo-1 (Molecular Probes). Parasitaemia was determined from dot plots (side scatter versus fluorescence) of $5 \times 10^{4}$ cells acquired on a FACSCalibur flow cytometer using CELLQUEST software (Becton Dickinson). Initial gating was carried out with unstained, uninfected erythrocytes to account for erythrocyte autofluorescence and analysis performed using Flow Jo 7.6.5 (TreeStar Inc).
Changes in mitochondrial membrane potential ( $\Psi \Delta$ mit) Loss of parasite mitochondrial membrane potential ( $\Psi \Delta$ mit) was determined using $5 \mu \mathrm{M}$ Mitrotracker Red CMXROS as described previously [18]. Cultures were incubated for $30 \mathrm{~min}$ at $37^{\circ} \mathrm{C}$ with the dye and then for $1 \mathrm{~h}$ with 10-fold serial dilutions (0.001-100 $\mu \mathrm{M})$ of $\mathrm{N} 3$ and atovaquone. As a control, $5 \mu \mathrm{M}$ cyanide $m$ chlorophenylhydrazone (CCCP), a protonophore that dissipate the membrane potential, was used. Results were analysed by flow cytometry as described above.

\section{Cytotoxicity assays}

The toxicity of hydroxynaphthoquinone derivatives toward HEK293T cells was evaluated with the 4,5dimethylthiazol- 2-yl-2,5- diphenyltetrazolium bromide (MTT) cell proliferation assay [19]. Cells $\left(1.0 \times 10^{5} /\right.$ well $)$ were seeded into 48 well plates and incubated in complete medium (Dulbecco's Modified Eagle Media, GIBCO, Life Technologies; supplemented with $10 \%$ foetal bovine serum, $100 \mu \mathrm{g} / \mathrm{ml}$ streptomycin and $100 \mathrm{U} / \mathrm{ml}$ penicillin) for $24 \mathrm{~h}$. Thereafter, medium was removed and replaced with complete medium $(450 \mu \mathrm{l} /$ well $)$; N3, atovaquone, and solvent (for controls) were added (0.128, 0.64, 3.2, 16, 80 and $400 \mu \mathrm{M})$ and cultures were incubated for 48 hours. Cells were then incubated with the MTT reagent for 3 hours, and absorbance was evaluated.

\section{Statistical analyses}

Analyses of parasitaemia were performed by a one-way analysis of variance test followed by post hoc analysis by the Dunnett's Multiple Comparison Test using GraphPad Prism software. $\mathrm{IC}_{50}$ values were produced using sigmoid dose-response curves on GraphPad software. At least three independent experiments were performed for each assay.

\section{Results}

In vitro activity of new hydroxynaphthoquinones

The ability of compounds N1-N5 to disrupt the in vitro growth of $P$. falciparum was tested. The naphthoquinones showed activity against $P$. falciparum, with $\mathrm{IC}_{50} \mathrm{~S}$ of 0.4$89 \mu \mathrm{M}$ (Figure 1 and Additional file 1: Figure S1). Only $\mathrm{N} 3 \mathrm{had}$ an $\mathrm{IC}_{50}$ in the $\mathrm{nM}$ range (443 nM; Figure 2).

\section{Cytotoxicity effects on cells HEK293T}

Cytotoxic activity against HEK293T cells was assessed with a tetrazolium-based colorimetric assay. No significant cytotoxicity was observed at concentrations below $16 \mu \mathrm{M}$. For N3, the concentration leading to $50 \%$ cell death $\left(\mathrm{CC}_{50}\right)$ was $54.6 \pm 0.23 \mu \mathrm{M}$ (Figure 1). For atovaquone the $\mathrm{CC}_{50}$ was $49 \pm 0.45 \mu \mathrm{M}$. 


\begin{tabular}{|c|c|c|c|}
\hline Compound & R1 & $\mathrm{IC}_{50}(\mu \mathrm{M} \pm \mathrm{SEM})^{\mathrm{a}}$ & $\mathrm{CC}_{50}(\mu \mathrm{M} \pm \mathrm{SEM})^{\mathrm{b}}$ \\
\hline N1 & $-\mathrm{H}$ & $89 \pm 0.12$ & - \\
\hline N2 & $-\mathrm{P}-\mathrm{NO}_{2} \mathrm{C}_{6} \mathrm{H}_{4}$ & $13.7 \pm 0.14$ & - \\
\hline N3 & $-\mathrm{C}_{6} \mathrm{H}_{5}$ & $0.44 \pm 0.08$ & $54.6 \pm 0.23$ \\
\hline N4 & $-\mathrm{P}-\mathrm{OCH}_{3} \mathrm{C}_{6} \mathrm{H}_{4}$ & $16 \pm 0.15$ & - \\
\hline N5 & $-\mathrm{CH}\left(\mathrm{CH}_{3}\right)_{2}$ & $15.2 \pm 0.1$ & - \\
\hline
\end{tabular}

Figure 1 Biological activity of hydroxynaphtoquinones. Structure and biological activity of compounds N1-N5.

Effect of N3 on $\Delta \Psi_{\text {mit }}$

It was also verified the effects of compound N3 on $P$. falciparum mitochondrial membrane potential ( $\triangle \Psi$ mit). Compound N3 showed an $\mathrm{IC}_{50 \Delta \Psi \text { mit }}=16 \mu \mathrm{M}$ and atovaquone an $\mathrm{IC}_{50 \Delta \Psi \text { mit }}=4.4 \mu \mathrm{M}$ (Figure 3).

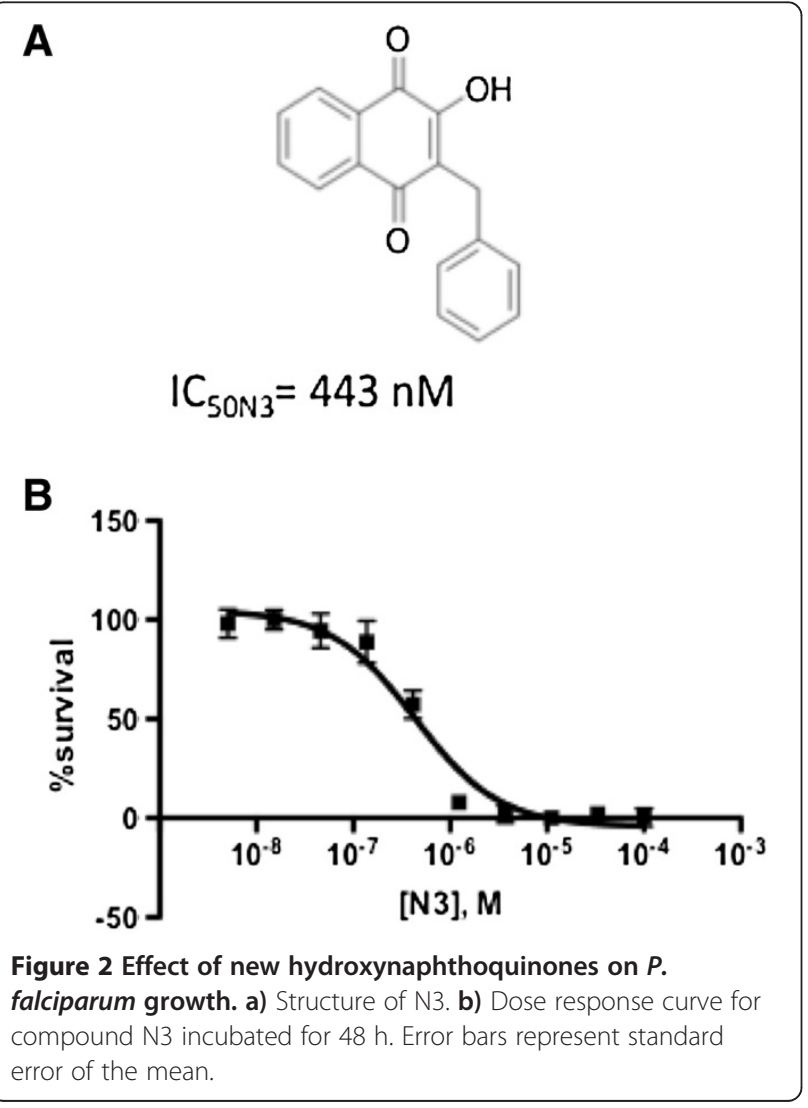

\section{Discussion}

In an attempt to identify improved anti-malarials, the antiparasitic activities of synthetic hydroxynaphthoquinones using in vitro assays was evaluated. It was identified one compound, N3, with nanomolar activity against P. falciparum, confirmed activity against mitochondrial electron transport, and showed limited cytotoxicity against human cells.

The cytochrome bc1 complex catalyses transfer of electrons to maintain the membrane potential of mitochondria, and it is a validated target for anti-malarial drugs. Atovaquone is the only hydroxynaphthoquinone and inhibitor of the bc1 complex currently used to treat malaria. It is generally efficacious, but suffers from irregular absorption (improved with fatty food), limited drug resistance, and high cost of production $[8,9,20]$. Work to counteract atovaquone limitations has identified other hydroxynaphthoquinones with anti-malarial activity [8]. One series contained an ester at the 3-hydroxy group of atovaquone, with nanomolar anti-malarial activity; addition of long side chains decreased activity [11]. A series of 26 compounds based on the structure of rhinacanthin, a naphthoquinone with anticancer properties, was synthesized [21]; two of these had nanomolar activity and inhibited the cytochrome bc1 complex of P. falciparum. Another four hydroxynaphthoquinones were synthesized in an attempt to circumvent resistance to atovaquone, which is mediated by mutations in the mitochondrial cytochrome $\mathrm{b}$ gene [13]. The addition of a methyl radical on the naphthoquinone ring provided excellent activity against atovaquone-resistant strains of $P$. falciparum, with documentation of inhibition of the cytochrome bc1 complex [13]. It was recently screened 36 new anti-malarial 


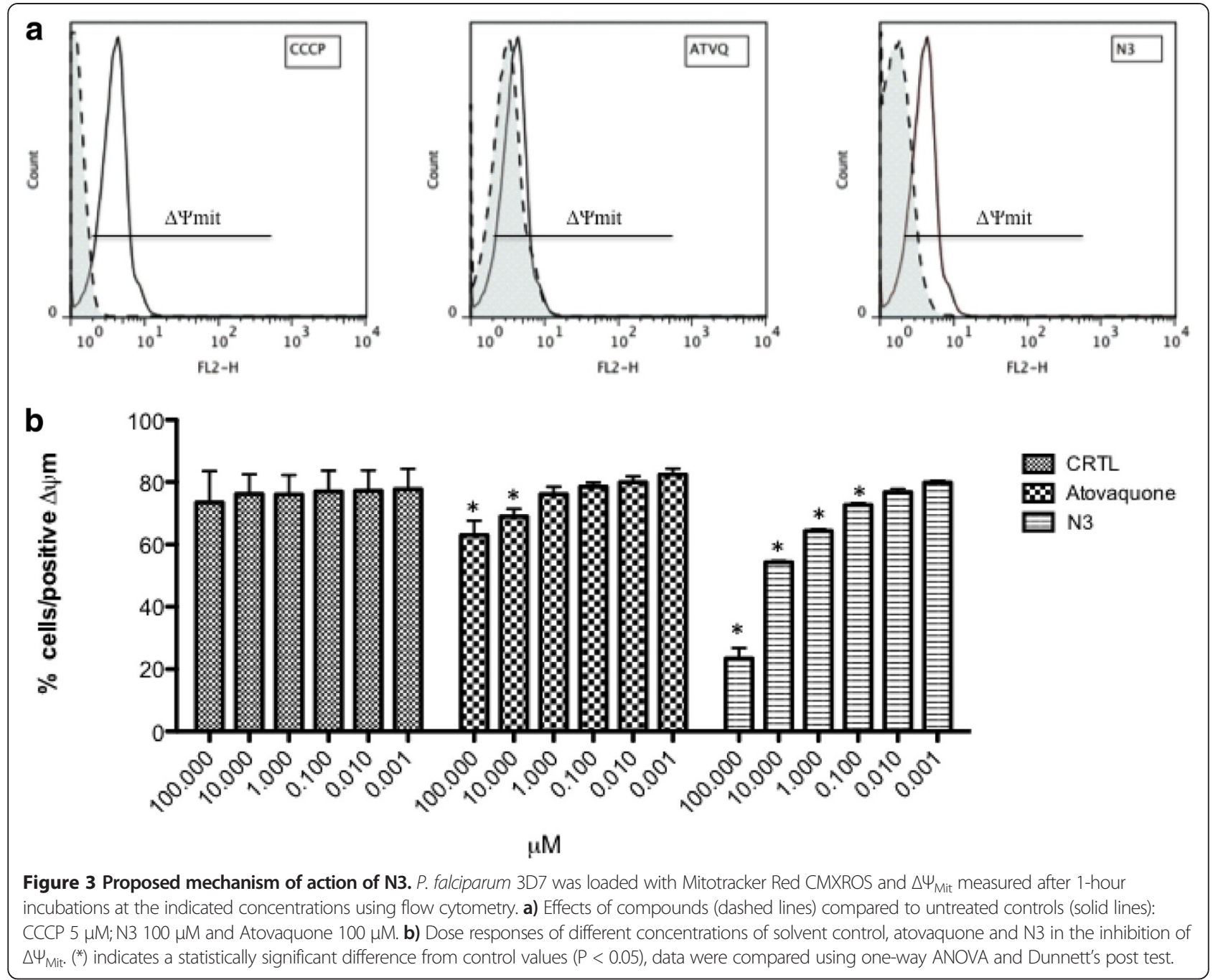

phenylsulfanylmethyl naphthoquinones structurally related to lapachol [22]. The compounds had moderate in vitro activity against $P$. falciparum.

Comparing the structures of atovaquone, N3 and BW58-C (an atovaquone precursor), these three structures are very similar in molecular volume, though N3 is much simpler to prepare and has no chiral centers (Figure 4) and, therefore, it can serve as a starting point for a new series of hydroxynaphthoquinone antimalarials. The results indicate that the cyclohexane ring of atovaquone is not essential for antimalarial activity, since its replacement by a $\mathrm{CH} 2$ group in $\mathrm{N} 3$ only slightly decreased activity, and N3 was capable of inhibiting mitochondrial activity efficiently (Figures 2 and 3). Considering BW58-C, this molecule showed excellent results against murine malaria [23] and good<smiles>CC(C)=C1C=C=C=C(C2=C(O)C(=O)c3ccccc3C2=O)C=C=C1</smiles>

2-(4-t-butylcyclohexyl)-3-hydroxy-1,4naphthoquinone (BW58-C)<smiles>N#CC1(c2ccccc2)C(=O)C(O)C(=O)c2ccccc21</smiles><smiles>CC(C)(C)OC(=O)C1=C=C=C(c2ccc(Cl)cc2)C=C=C(C2=C(O)C(=O)c3ccccc3C2=O)C=C1</smiles>

Atovaquone

Figure 4 Structure of BW58-C, N3 and atovaquone pointing the main chemistry differences of compounds. Circles in the figure represent chiral centers. 
activity against respiration of mitochondria [24], but it was rapidly metabolized and eliminated in humans [25]. Interaction with cytochrome P450 enzymes and other aspects of metabolism are important components of drug design, and evaluation of the metabolism of N3 is needed.

Screening of a library of 2-hydroxy-naphthoquinones found compounds with alkyl side-chains that effectively inhibited the yeast $b c 1$ complex [26]. In the present study, was evaluated 5 additional hydroxynaphthoquinones, and demonstrated that one of these, N3, was a potent inhibitor of mitochondrial electron transport, had nanomolar activity against cultured P. falciparum, and showed minimal cytotoxicity. Optimization of N3 thus offers potential for new candidate compounds to treat and prevent malaria.

\section{Additional file}

\section{Additional file 1: Figure S1. Structures of other}

hydroxynaphthoquinones and effects on $P$. falciparum growth. Different concentrations of compounds were incubated for $48 \mathrm{~h}$ with $P$. falciparum. Results are shown as a dose response curve for compound N1, N2, N4 and N5 incubated for 48 h. Error bars represent standard error of the mean.

\section{Competing interests}

The authors declare that they have no competing interests.

\section{Authors' contributions}

DCS carried out the in vitro assays and drafted the manuscript. SBF and DRR carried out the chemical synthesis and collaborated in the elaboration of the manuscript. LNC and MN carried out the cytotoxicity test and collaborated in the elaboration of the manuscript. MN carried out the Plasmodium culture and collaborated in the elaboration of the manuscript. CRSG and VFF conceived of the study, and participated in its design and coordination and collaborated in the elaboration of the manuscript. All authors read and approved the final manuscript.

\section{Acknowledgments \\ This work was supported by FAPESP (Fundação de Amparo a Pesquisa de São Paulo) (07/52924-0), by Malaria Pronex, and by a INCT-INBqMed (Instituto Nacional de Ciência e Tecnologia- Instituto Nacional de Ciência e Tecnologia de Biotecnologia Estrutural e Química Medicinal em Doenças Infecciosa) grant. C.R.S. Garcia and V. Ferreira are CNPQ (Conselho Nacional de Pesquisa) fellows. D.S. received a CAPES (Coordenação de Aperfeiçoamento de Pessoal de Nível Superior) Fellowship. D.R. da Rocha thanks FAPERJ (Fundação de Amparo a Pesquisa do Rio De Janeiro) for their doctoral fellowship. LNC and MM received a FAPESP Fellowship. Thanks are due to the CNPQ, CAPES and FAPERJ for funding this work.}

\section{Author details}

'Departamento de Fisiologia, Universidade de São Paulo, São Paulo 05508-900, Brazil. Departamento de Química Orgânica, Universidade Federal Fluminense, Niterói 24020-141, Brazil. Departamento de Química Orgânica, Universidade Federal do Rio de Janeiro, Macaé 27930-560, Brazil. ${ }^{4}$ Department of Medicine, University of California, San Francisco, CA 94143, USA. ${ }^{5}$ Universidade de São Paulo, Instituto de Biociências, Rua do Matão, travessa 14, n.321 Cidade Universitária, CEP 05508-900 São Paulo, SP, Brazil.

Received: 14 December 2012 Accepted: 12 June 2013

Published: 10 July 2013

\section{References}

1. Gazarini ML, Sigolo CA, Markus RP, Thomas AP, Garcia CR: Antimalarial drugs disrupt ion homeostasis in malarial parasites. Mem Inst Oswaldo Cruz 2007, 102:329-334.

2. Garcia CR, de Azevedo MF, Wunderlich G, Budu A, Young JA, Bannister L: Plasmodium in the postgenomic era: new insights into the molecular cell biology of malaria parasites. Int Rev Cell Mol Biol 2008, 266:85-156.

3. Schlitzer M: Malaria chemotherapeutics part I: History of antimalarial drug development, currently used therapeutics, and drugs in clinical development. Chem Med Chem 2007, 2:944-986.

4. WHO: World Malaria Report. Geneva: World Health Organization; 2010.

5. Srivastava IK, Rottenberg $H$, Vaidya $A B$ : Atovaquone, a broad spectrum antiparasitic drug, collapses mitochondrial membrane potential in a malarial parasite. J Biol Chem 1997, 272:3961-3966.

6. Hooker SC: Lomatiol. II. Its occurrence, constitution, relation to and conversion into lapachol. Also a synthesis of lapachol. J Am Chem Soc 1936, 58:1181-1190.

7. Fieser LF, Berliner E, Bondhus FJ, Chang FC, Dauben WG, Ettlinger MG, Fields GFM, Fieser M, Heidelberger C, Heymann H, Seligman AM, Vaughan WR, Wilson AG, Wilson E, Wu M, Leffler MT, Hamlin KE, Hathaway RJ, Matson EJ, Moore EE, Moore MB, Rapala RT, Zaugg HE: Naphthoquinone antimalarials.4.5.6.7.8.9.10.11. synthesis. J Am Chem Soc 1948, 70:3174-3215

8. Barton V, Fisher N, Biagini GA, Ward SA, O'Neill PM: Inhibiting Plasmodium cytochrome bc1: a complex issue. Curr Opin Chem Biol 2010, 14:440-446.

9. Baggish AL, Hill DR: Antiparasitic agent atovaquone. Antimicrob Agents Chemother 2002, 46:1163-1173.

10. Dressman JB, Reppas C: In vitro-in vivo correlations for lipophilic, poorly water-soluble drugs. Eur J Pharm Sci 2000, 11(Suppl 2):S73-S80.

11. Danoun S, Baziard-Mouysset G, Stigliani J, Ane-Margail M, Payard M, Leger J, Canron X, Vial H, Loiseau P, Bories C, Recoche C: Synthesis and protozoocidal activity of new 1,4-naphthoquinones. Heterocycl Comm 1999, 5:343-348

12. El Hage S, Ane M, Stigliani J, Marjorie M, Vial H, Baziard-Mouysset G, Payard $\mathrm{M}$ : Synthesis and antimalarial activity of new atovaquone derivatives. Eur J Med Chem 2009, 44:4778-4782.

13. Hughes L, Lanteri C, O'Neil M, Johnson J, Gribble G, Trumpower B: Design of anti-parasitic and anti-fungal hydroxy-naphthoquinones that are less susceptible to drug resistance. Mol Biochem Parasitol 2011, 177:12-19.

14. Hughes L, Covian R, Gribble G, Trumpower B: Probing binding determinants in center $P$ of the cytochrome bc(1) complex using novel hydroxy-naphthoquinones. Biochim Biophys Acta 2010, 1797:38-43.

15. Ferreira S, da Rocha D, Carneiro J, Santos W, Ferreira V: A new method to prepare 3-Alkyl-2-hydroxy-1,4-naphthoquinones: synthesis of lapachol and phthiocol. Synlett 2011, 2011:1551-1554.

16. Trager $W$, Jensen J: Human malaria parasites in continuous culture. Science 1976, 193:673-675.

17. Lambros C, Vanderberg J: Synchronization of Plasmodium falciparum erythrocytic stages in culture. J Parasitol 1979, 65:418-420.

18. Jogdand PS, Singh SK, Christiansen M, Dziegiel MH, Singh S, Theisen M: Flow cytometric readout based on Mitotracker Red CMXRos staining of live asexual blood stage malarial parasites reliably assesses antibody dependent cellular inhibition. Malar J 2012, 11:235.

19. Carmichael J, DeGraff WG, Gazdar AF, Minna JD, Mitchell JB: Evaluation of a tetrazolium-based semiautomated colorimetric assay: assessment of chemosensitivity testing. Cancer Res 1987, 47:936-942.

20. Kessl JJ, Meshnick SR, Trumpower BL: Modeling the molecular basis of atovaquone resistance in parasites and pathogenic fungi. Trends Parasitol 2007, 23:494-501.

21. Kongkathip N, Pradidphol N, Hasitapan K, Grigg R, Kao WC, Hunte C, Fisher N, Warman AJ, Biagini GA, Kongsaeree P, Chuawong P, Kongkathip B: Transforming rhinacanthin analogues from potent anticancer agents into potent antimalarial agents. J Med Chem 2010, 53:1211-1221.

22. Sharma A, Santos I, Gaur P, Ferreira V, Garcia C, Rochab D: Addition of thiols to o-quinone methide: New 2-hydroxy-3-phenylsulfanylmethyl $[1,4]$ naphthoquinones and their activity against the human malaria parasite Plasmodium falciparum (3D7). Eur J Med Chem 2013, 59:48-53.

23. Hudson A, Randall A, Fry M, Ginger C, Hill B, Latter V, McHardy N, Williams R: Novel anti-malarial hydroxynaphthoquinones with potent broad spectrum anti-protozoal activity. Parasitology 1985, 90:45-55. 
24. Hammond D, Burchell J, Pudney M: Inhibition of pyrimidine biosynthesis de novo in Plasmodium falciparum by 2-(4-t-butylcyclohexyl)-3-hydroxy1,4-naphthoquinone in vitro. Mol Biochem Parasitol 1985, 14:97-109.

25. Weaver R, Dickins M, Burke M: Cytochrome P450 2C9 is responsible for hydroxylation of the naphthoquinone antimalarial drug $58 \mathrm{C} 80$ in human liver. Biochem Pharmacol 1993, 46:1183-1197.

26. Kessl JJ, Moskalev NV, Gribble GW, Nasr M, Meshnick SR, Trumpower BL: Parameters determining the relative efficacy of hydroxynaphthoquinone inhibitors of the cytochrome bc1 complex. Biochim Biophys Acta 2007, 1767:319-326.

doi:10.1186/1475-2875-12-234

Cite this article as: Schuck et al:: Biological evaluation of

hydroxynaphthoquinones as anti-malarials. Malaria Journal 2013 12:234.

\section{Submit your next manuscript to BioMed Central} and take full advantage of:

- Convenient online submission

- Thorough peer review

- No space constraints or color figure charges

- Immediate publication on acceptance

- Inclusion in PubMed, CAS, Scopus and Google Scholar

- Research which is freely available for redistribution 